\title{
Determinants of knowledge of HIV status in South Africa: results from a population-based HIV survey
} Karl Peltzer*1,2, Gladys Matseke ${ }^{1}$, Thembile Mzolo ${ }^{1}$ and Mmapaseka Majaja ${ }^{1}$

\author{
Address: ${ }^{1}$ Health Promotion Research Unit, Social Aspect of HIV/AIDS and Health, Human Sciences Research Council, Pretoria, South Africa and \\ ${ }^{2}$ Department of Psychology, University of the Free State, Bloemfontein, South Africa \\ Email: Karl Peltzer* - kpeltzer@hsrc.ac.za; Gladys Matseke - gmatseke@hsrc.ac.za; Thembile Mzolo - tmzolo@hsrc.ac.za; \\ Mmapaseka Majaja - mmajaja@hsrc.ac.za \\ * Corresponding author
}

Published: 5 June 2009

BMC Public Health 2009, 9:174 doi:10.1 186/147|-2458-9-174
Received: 3 March 2009

Accepted: 5 June 2009

This article is available from: http://www.biomedcentral.com/I47/-2458/9/174

(C) 2009 Peltzer et al; licensee BioMed Central Ltd.

This is an Open Access article distributed under the terms of the Creative Commons Attribution License (http://creativecommons.org/licenses/by/2.0), which permits unrestricted use, distribution, and reproduction in any medium, provided the original work is properly cited.

\begin{abstract}
Background: Over 30\% of women and men in the South African national HIV household of 2005 indicated that they had previously been tested for HIV (of which 91\% were aware of their test results). This paper seeks to describe the associations between socio-demographic, behavioural and social characteristics and knowledge of HIV status among a nationally representative population in South Africa.

Methods: A multistage probability sample involving 16395 male and female respondents, aged 15 years or older was selected. The sample was representative of the South African population by age, race, province and type of living area, e.g. urban formal, urban informal, etc. Respondents were interviewed on HIV knowledge, perceptions and behaviour and provided blood for research HIV testing. Bivariate and multivariate logistic regression was used to identify socio-demographic, social and behavioural factors associated with knowledge of HIV status.

Results: From the total sample $27.6 \%$ ever and $7.8 \%$ knew their HIV status in the past 12 months. In multivariate analyses being female, the age group 25 to 34 years old, other than African Black population group (White, Coloured, Asian), higher educational level, being employed, urban residence, awareness of a place nearby where one could be tested for HIV, impact of HIV on the household and having had two of more sexual partners in the past year were associated with knowledge of HIV status. Among HIV positive persons awareness of a place nearby where one could be tested for HIV and impact of HIV on the household were associated knowledge of HIV status, and among HIV negative persons HIV risk behaviour (multiple partners, no condom use), awareness of a place nearby where one could be tested for HIV, higher knowledge score on HIV and knowledge of serodiscordance were associated knowledge of HIV status.
\end{abstract}

Conclusion: Education about HIVIAIDS and access to HIV counselling and testing (HCT) in rural areas, in particular among the Black African population group needs to be improved, in order to enhance the uptake of HIV counselling and testing services, an essential step for the initiation of treatment. 


\section{Background}

HIV Counselling and Testing (HCT) is an entry point to both prevention and treatment. People have to know their HIV sero-status to enable them to seek appropriate treatment as well as enable them to choose prevention strategies. It has become increasingly important in the global response to HIV/AIDS. HCT services need to be available and accessible to the entire public to enable their easy utilization. Although most South Africans are aware that HCT services are available, only one in five people in South Africa who know about HCT have been tested for HIV [1]. Bunnell [2] found in a cross-sectional and nationally representative study (2004-2005 Uganda HIV/ AIDS Sero-Behavioral Survey) that $21 \%$ of adults knew their HIV status. Among countries in Southern Africa the percentage who took an HIV test in the last 12 months and who know their results ranges between $2 \%$ in Mozambique to $20 \%$ in Botswana [3], and in the US $10.4 \%[4]$.

Various factors have been identified for the low uptake of HCT: (1) socio-economic factors such as age [5-9], marital status [8], educational level $[6,10,11]$, occupation [7], household wealth [10], and area of residence [8]; (2) social factors such as fear of unsolicited disclosure, fear of stigma and discrimination $[1,6,7,9,12,13]$, client-counsellor dynamics including lack of confidentiality $[11,14,15]$; (3) proximity and access to VCT site $[6,9,12,16,17]$; (4) HIV knowledge including prior knowledge of VCT sites and HIV risk perception and HIV risk behaviour $[7,8,10,11,18,19]$; and (5) health status $[5,7,8]$.

Various studies in South Africa have also shown that the uptake of HCT also differs depending on the counselling and testing model used, the use of HCT testing kits, other than rapid testing kits across different populations of high HIV prevalence [20-23]. There is lack of information on determinants of knowledge of HIV status in South Africa. Therefore, this study investigates the determinants of knowledge of HIV status in South Africa using secondary data analysis from a national population-based HIV survey.

\section{Methods \\ Sample and procedure}

The survey targeted all persons over 2 years of age living in South Africa and residing in homes, i.e. excluding individuals living in educational institutions, old-age homes, hospitals and uniformed service barracks but including those living in hostels. The survey applied a multi-stage stratified sampling approach based on a master sample consisting of 1000 enumerator areas (EAs) used by Statistics South Africa for the national census in 2001. Three persons in each household were potentially eligible to be selected for the survey; however only one was selected from each of the age groups 2-14 years, 15-24 years, and 25 years and older. The sample included in this analysis includes the age group 15 years and above (range 15 to 96) 16395 (59.1\% Black Africans, 18.4\% Coloureds, $11.7 \%$ Whites and $10.8 \%$ Indian or Asians) of which 12 032 were interviewed and tested for HIV and 4363 who were interviewed but not tested for HIV. Linked anonymous HIV testing was performed using dried blood spot (DBS) specimens. Socio-demographic and behavioural information was collected with questionnaires administered by trained fieldworkers [5].

Ethical approval for conducting the study was obtained from the Human Sciences Research Council's Ethics Committee (Application Number REC5/24/04). Informed consent was obtained separately for agreeing to participate in the interview and for providing a specimen for HIV testing.

\section{Measures}

HIV antibody testing: Using DBS spots all samples were first tested with Vironostika HIV-1 Uniform II Plus O assay (bioMerieux); all HIV positive samples were retested with a second ELISA test (Vitros ECI, Ortho Clinical Diagnostics) (Shisana et al., 2005).

The questionnaire included demographic variables such as age, sex, formal education completed, marital status and socioeconomic status.

HIV testing history: The survey included questions concerning history of HIV antibody testing. These measures were used to classify participants into groups based on whether they had been tested for HIV and knew their results. Participants who reported having been tested for HIV indicated their HIV awareness status of their most recent test, or that they did not know the results.

HIV risk behaviour history: To assess HIV risk history, participants indicated the number of sex partners they had in the previous 12 months, had symptoms of a sexually transmitted infection (STI), and whether they had ever used a condom, a condom with their last sexual partner and their last sexual non-regular partner. All responses were dichotomous indicating the occurrence or nonoccurrence of each risk factor.

HIV knowledge: A 7-item HIV knowledge test was used, e.g. Is it possible to transmit HIV through unprotected sex? Response options were yes, no, does not know. Responses were scored for the number of correct responses; with don't know responses scored incorrect, range $0-6$. Scores were coded into three levels low $=5$ correct responses; medium $=6$ correct responses, and high $=$ 
7 correct responses. Cronbach's alpha for the HIV knowledge index was .70 for this sample.

ARV knowledge was assessed with one item: "Have you ever heard about new drug treatments for people with AIDS called antiretrovirals or ARVs?" Response option was "Yes" or "No".

HIV impact: Participants responded to three HIV impact items, ever anyone in the household ever been diagnosed with HIV-AIDS, is there a person in the household who is bed-ridden with an AIDS related illness and past year occurrence of AIDS-related death of household member. Response options were "yes or no"; any yes was scored with "1".

AIDS stigma attitudes: Five AIDS stigma items were adapted from previous research and developed for use in South Africa, e.g. "I would be willing to care for a family member with AIDS". Response options were, yes, no, do not know; "no and Do not know were coded one and yes coded "0". A total score was calculated, (range 0-5), and coded into three levels $0=$ scores low AIDS stigma, medium 1-2 and 3-5 scores high AIDS stigma. Cronbach's alpha for the AIDS stigma index was .62 for this sample.

Demographic variables included sex, age, marital status, population group (Black African, White, Coloured, Indian or Asian), formal education, employment status and place of residence.

\section{Data analysis}

Data analysis was performed using STATA software version 10.0 (Stata Corporation, College Station, Texas, USA). The analysis in STATA took into account the multilevel stratified cluster sample design of the study. We obtained frequencies as estimation of prevalence of knowledge of HIV status. We also conducted logistic regression analysis to estimate the association between relevant predictor variables and knowledge of HIV status. The predictor variables were identified from the literature as possible factors that may be associated with knowledge of HIV status [5-19]. We report unadjusted odds ratios for selected predictor variables (sex, age, marital status, formal education, population group, employment status, geolocality, awareness of HIV test site, HIV knowledge, knowledge of ARVs, knowledge of HIV serodiscordance, impact of HIV, HIV risk perception, HIV stigma attitudes, HIV status, history of STI symptoms, number of sexual partners in the past year, no condom use at last sex, no condom use with last non-regular partner) while considering knowledge of HIV status as a dependent variable, and knowledge of HIV status separately for HIV positive and HIV negative as dependent variables. We therefore report results of adjusted odds ratios for the factors, having controlled for factors as significant in the bivariate analysis. The dependent variable was knowledge of HIV status, and the independent variables were factors which significantly increased knowledge of HIV status in the bivariate analysis. In the analysis, weighted percentages are reported. The reported sample size refers to the sample that was asked the target question. The two-sided 95\% confidence intervals are reported. The p-value less or equal to $5 \%$ is used to indicate statistical significance. Both the reported 95\% confidence intervals and the pvalue are adjusted for the multi-stage stratified cluster sample design of the study.

\section{Results}

From the total sample of 1639515 years and above, $27.6 \%$ (CI $=26.5-28.7)$ reported to have ever had an HIV test and had received their HIV test results (knowledge of HIV status). Of those who had been tested for HIV, 38.8\% had been tested within the year preceding the survey, $33.1 \% 1$ to 2 years previously, and $28.2 \%$ more than 2 years previously; $7.8 \%$ of the total sample had taken an HIV test in the past 12 months and knew their test result.

In bivariate analyses being female, the age group 25 to 34 years old, being married or cohabitating, Grade 12 and more formal education, other than African Black population group (White, Coloured, Asian), being employed, urban residence, awareness of a place nearby where one could be tested for HIV, higher knowledge score on HIV, knowledge of serodiscordance, impact of HIV on the household, high HIV risk perception, being HIV positive (from the survey), one, two or more sexual partners in the past year and non-condom use at last sex were associated with knowledge of HIV status. In multivariate analyses being female, the age group 25 to 34 years old, other than African Black population group (White, Coloured, Asian), higher educational level, being employed, urban residence, awareness of a place nearby where one could be tested for HIV, impact of HIV on the household and two or more sexual partners in the past year were associated with knowledge of HIV status, and marital status, HIV knowledge, knowledge of serodiscordance, HIV risk perception, HIV status and no condom at last sex were no longer associated with knowledge of HIV status. A large proportion $(39.5 \%, 38.2,40.7)$ indicated that they had not heard about antiretroviral treatment (see Table 1).

Bivariate analyses with demographic variables and knowledge of HIV status among HIV positive and negative persons separately found among HIV positive persons that higher levels of formal education, being White, Coloured or Asian, and urban residence were associated knowledge of HIV status, and among HIV negative persons being female, the age group 25 to 34 years old, being married or 
Table I: Bivariate and multivarivate analyses of factors associated with knowledge of HIV status

$\mathrm{N} \quad$ Know HIV test result (\%) $\quad$ Crude OR $(95 \% \mathrm{Cl}) \quad$ P-value $\quad$ Adjusted OR

$(95 \% \mathrm{Cl})$ (Pseudo R square $=.15)$

\begin{tabular}{|c|c|c|c|c|c|c|}
\hline \multicolumn{7}{|l|}{ Demographics } \\
\hline Sex & & & & 0.000 & & \\
\hline Men & 1588 & 24.6 & 1.00 & & 1.00 & \\
\hline Women & 2851 & 30.1 & $1.32(1.18-1.48)$ & 0.000 & $1.93(1.52-2.43)$ & 0.000 \\
\hline Age & & & & 0.000 & & \\
\hline $15-24$ & 1065 & 17.7 & 1.00 & & 1.00 & \\
\hline $25-34$ & 1164 & 40.8 & $3.20(2.7 \mathrm{I}-3.78)$ & 0.000 & $1.83(1.38-2.42)$ & 0.000 \\
\hline 35 and more & 2210 & 27.6 & $1.77(1.55-2.02)$ & 0.000 & $1.22(0.87-1.7 I)$ & 0.259 \\
\hline Marital status & & & & 0.000 & & \\
\hline Single & 1662 & 22.9 & 1.00 & & 1.00 & \\
\hline Married/cobabitating & 2318 & 34.6 & $1.78(1.58-2.01)$ & 0.000 & $1.35(1.00-1.83)$ & 0.051 \\
\hline Divorced/separated/widowed & 436 & 21.7 & $0.93(0.78-1.11)$ & 0.452 & $1.41(0.95-2.10)$ & 0.087 \\
\hline Education & & & & 0.000 & & \\
\hline Grade 7 or less & 688 & 16.0 & 1.00 & & 1.00 & \\
\hline Grade 8 to II & 1509 & 22.6 & $1.53(1.31-1.79)$ & 0.000 & $0.96(0.67-1.36)$ & 0.800 \\
\hline Grade 12 and more & 2231 & 42.3 & $4.34(3.72-5.07)$ & 0.000 & $1.50(1.08-2.10)$ & 0.016 \\
\hline Population group & & & & 0.000 & & \\
\hline Black African & 2182 & 23.8 & 1.00 & & 1.00 & \\
\hline Other & 2247 & 40.5 & $2.17(1.92-2.45)$ & 0.000 & $1.42(1.10-1.84)$ & 0.007 \\
\hline Employment status & & & & 0.000 & & \\
\hline Not employed & 2191 & 21.1 & 1.00 & & 1.00 & \\
\hline Employed & 2158 & 41.0 & $2.60(2.30-2.94)$ & 0.000 & $1.50(1.18-1.91)$ & 0.001 \\
\hline Geolocality & & & & 0.000 & & \\
\hline Rural & 872 & 17.8 & 1.00 & & 1.00 & \\
\hline Urban & 3567 & 35.0 & $2.49(2.20-2.8 \mathrm{I})$ & 0.000 & $1.96(1.5 \mathrm{I}-2.55)$ & 0.000 \\
\hline
\end{tabular}

\section{HIV knowledge and attitudes}

\begin{tabular}{|c|c|c|c|c|c|c|}
\hline \multicolumn{4}{|l|}{$\begin{array}{l}\text { Aware of place nearby where one } \\
\text { could be tested for HIV }\end{array}$} & \multicolumn{3}{|l|}{0.000} \\
\hline No & 142 & 4.4 & 1.00 & & 1.00 & \\
\hline Yes & 4287 & 33.9 & II.05 (8.30-|4.7I) & 0.000 & $7.86(4.92-12.55)$ & 0.000 \\
\hline HIV knowledge & & & & 0.000 & & \\
\hline Low & 981 & 20.3 & 1.00 & & 1.00 & \\
\hline Medium & 1492 & 29.0 & $1.60(1.38-1.85)$ & 0.000 & $0.91(0.68-1.22)$ & 0.535 \\
\hline High & 1898 & 32.6 & $1.90(1.65-2.17)$ & 0.000 & $1.19(0.90-1.56)$ & 0.218 \\
\hline Knowledge of $A R V s$ & & & & 0.897 & & \\
\hline No & 1715 & 27.9 & 1.00 & & & \\
\hline Yes & 2695 & 27.7 & $0.99(0.89-1.11)$ & 0.897 & --- & \\
\hline Know of serodiscordance & & & & 0.000 & & \\
\hline No & 1529 & 21.0 & 1.00 & & 1.00 & \\
\hline Yes & 2892 & 33.7 & $1.92(1.71-2.15)$ & 0.000 & $1.04(0.83-1.31)$ & 0.715 \\
\hline $\begin{array}{l}\text { Impact of HIV } \\
\text { (household: HIV, care, death) }\end{array}$ & & & & 0.000 & & \\
\hline No & 4180 & 26.7 & 1.00 & & 1.00 & \\
\hline Yes & 259 & 43.0 & $2.08(1.66-2.60)$ & 0.000 & $2.82(I .8 I-4.4 I)$ & 0.000 \\
\hline
\end{tabular}


Table I: Bivariate and multivarivate analyses of factors associated with knowledge of HIV status (Continued)

\begin{tabular}{|c|c|c|c|c|c|c|}
\hline HIV risk perception & & & & 0.000 & & \\
\hline Low & 1476 & 24.3 & 1.00 & & 1.00 & \\
\hline Medium & $|45|$ & 27.3 & $1.00(0.88-1.12)$ & 0.961 & $0.94(0.72-1.22)$ & 0.635 \\
\hline High & 1492 & 30.8 & $1.18(1.10-1.26)$ & 0.000 & $0.90(0.67-1.20)$ & 0.469 \\
\hline AIDS stigma attitudes & & & & 0.551 & & \\
\hline Low & 2023 & 32.0 & 1.00 & & & \\
\hline Medium & 1995 & 25.4 & $1.02(0.90-1.15)$ & 0.735 & --- & \\
\hline High & 378 & 21.8 & $1.06(0.88-1.28)$ & 0.549 & & \\
\hline \multicolumn{7}{|l|}{ HIV status and risk behaviour } \\
\hline HIV status & & & & 0.000 & & \\
\hline Negative & 2782 & 26.4 & 1.00 & & 1.00 & \\
\hline Postive & 436 & 32.7 & $1.35(1.13-1.62)$ & 0.000 & $0.93(0.69-1.24)$ & 0.618 \\
\hline Ever STI symptoms & & & & 0.682 & & \\
\hline No & 3708 & 27.5 & 1.00 & & & \\
\hline Yes & 173 & 28.7 & $1.06(0.80-1.40)$ & 0.682 & --- & \\
\hline $\begin{array}{l}\text { Number of sexual partners in past } \\
\text { year }\end{array}$ & & & & 0.000 & & \\
\hline None & 1064 & 15.5 & 1.00 & & 1.00 & \\
\hline One & 3149 & 35.7 & $3.03(2.67-3.44)$ & 0.000 & $1.22(0.92-1.61)$ & 0.176 \\
\hline Two or more & 226 & 32.4 & $2.62(2.0 \mathrm{I}-3.4 \mathrm{I})$ & 0.000 & $1.65(1.07-2.53)$ & 0.022 \\
\hline No condom use at last sex & & & & 0.000 & & \\
\hline No & 1308 & 35.9 & 1.00 & & 1.00 & \\
\hline Yes & 1295 & 45.4 & $1.49(1.24-1.78)$ & 0.000 & I.I2(0.87-I.43) & 0.376 \\
\hline $\begin{array}{l}\text { No condom use with last non-regular } \\
\text { partner }\end{array}$ & & & & 0.677 & & \\
\hline No & 208 & 35.5 & 1.00 & & & \\
\hline Yes & 309 & 37.2 & $1.07(0.77-1.50)$ & 0.677 & --- & \\
\hline
\end{tabular}

cohabitating, higher educational levels, being White, Coloured or Asian, urban residence and being employed were associated with knowledge of HIV status.

Multivariate analyses with demographic variables and knowledge of HIV status among HIV positive and negative persons separately found among HIV positive persons that urban residence and being White, Coloured or Asian were associated with knowledge of HIV status, and among HIV negative persons being female, the age group 25 to 34 years old, being married or cohabitating, higher educational levels, being White, Coloured or Asian, urban residence and being employed were associated with knowledge of HIV status (see Table 2).

Bivariate analyses with behavioural factors (adjusted for sex and age) and knowledge of HIV status found among HIV positive persons no associations between behavioural risk factors and knowledge of HIV status, and among HIV negative persons bivariate and multivariate analyses (adjusted for sex and age) found that one, two or more sexual partners in the past 12 month and no con- dom use at last sex were associated knowledge of HIV status (see Table 3).

Bivariate analyses with HIV knowledge and risk variables (adjusted for sex and age) and knowledge of HIV status found among HIV positive persons that awareness of a place nearby where one could be tested for HIV, higher knowledge score on ARVs, knowledge of serodiscordance, impact of HIV on the household and high HIV risk perception were associated knowledge of HIV status, and among HIV negative persons awareness of a place nearby where one could be tested for HIV, high HIV knowledge score, knowledge of serodiscordance, impact of HIV on the household and high HIV risk perception were associated with knowledge of HIV status.

Multivariate analyses with HIV knowledge and risk variables (adjusted for sex and age) and knowledge of HIV status found among HIV positive persons that awareness of a place nearby where one could be tested for HIV, impact of HIV on the household and high HIV risk perception were associated knowledge of HIV status, and among HIV 
Table 2: Bivariate and multivarivate analyses of demographic factors associated with knowledge of HIV status among HIV positive and negative persons

\begin{tabular}{|c|c|c|c|c|c|c|}
\hline \multirow[t]{2}{*}{ Demographic variables } & \multicolumn{6}{|c|}{ HIV positive } \\
\hline & $\mathrm{N}$ & Know HIV test result (\%) & Crude OR $(95 \% \mathrm{Cl})$ & $\mathrm{P}$ - value & $\begin{array}{l}\text { Adjusted OR } \\
(95 \% \mathrm{Cl})(\text { Pseudo R square }=.04)\end{array}$ & P-value \\
\hline Gender & & & & 0.146 & & \\
\hline Men & 104 & 28.7 & 1.00 & & & \\
\hline Women & 332 & 34.7 & $1.32(0.91-1.91)$ & 0.146 & --- & \\
\hline Age & & & & 0.351 & & \\
\hline I5-24 yrs & 109 & 31.3 & 1.00 & & & \\
\hline $25-34$ & 164 & 35.5 & $1.21(0.79-1.85)$ & 0.377 & & \\
\hline $35+$ & 163 & 30.5 & $0.96(0.63-1.47)$ & 0.862 & --- & \\
\hline Marital status & & & & 0.755 & & \\
\hline Single & 235 & 31.7 & 1.00 & & & \\
\hline Married/cohabiting & 150 & 34.6 & I.14 (0.79-I.64) & 0.482 & & \\
\hline Divorced/separated/widowed & 51 & 31.3 & $0.98(0.59-1.63)$ & 0.932 & --- & \\
\hline Educational level & & & & 0.016 & & \\
\hline Grade 7 or less & 119 & 26.1 & 1.00 & & 1.00 & \\
\hline Grade 8 to 11 & 198 & 34.8 & $1.51(1.01-2.24)$ & 0.043 & $1.38(0.92-2.07)$ & 0.116 \\
\hline Grade $12+$ & 118 & 37.8 & $1.72(1.09-2.76)$ & 0.019 & $1.56(0.98-2.46)$ & 0.059 \\
\hline Population group & & & & 0.000 & & \\
\hline Black African & 396 & 32.2 & 1.00 & & 1.00 & \\
\hline Other & 40 & 54.1 & $2.49(|.4|-4.4 \mid)$ & 0.000 & $2.04(I . \mid 2-3.7 I)$ & 0.020 \\
\hline Geolocality & & & & 0.000 & & \\
\hline Rural & 120 & 23.2 & 1.00 & & 1.00 & \\
\hline Urban & 316 & 40.5 & $2.25(1.59-3.88)$ & 0.000 & $2.14(1.50-3.04)$ & 0.000 \\
\hline Employment status & & & & 0.579 & & \\
\hline Not employed & 296 & 33.2 & 1.00 & & & \\
\hline Employed & 130 & 31.0 & $0.90(0.63-1.29)$ & 0.579 & --- & \\
\hline Demographic variables & & & HIV r & legative & & \\
\hline Gender & & & & 0.001 & & \\
\hline Men & 994 & 24.0 & 1.00 & & 1.00 & \\
\hline Women & 1708 & 28.5 & $1.41(1.14-1.75)$ & 0.001 & $1.65(1.37-1.97)$ & 0.000 \\
\hline Age & & & & 0.000 & & \\
\hline I5-24 yrs & 681 & 17.0 & 1.00 & & 1.00 & \\
\hline $25-34$ & 701 & 42.0 & $3.88(2.88-5.22)$ & 0.000 & $2.30(1.79-2.96)$ & 0.000 \\
\hline $35+$ & 1400 & 26.0 & $2.41(1.89-3.08)$ & 0.000 & $1.36(1.04-1.79)$ & 0.026 \\
\hline Marital status & & & & 0.002 & & \\
\hline Single & 1934 & 22.1 & 1.00 & & 1.00 & \\
\hline Married/cohabiting & 1468 & 32.8 & $1.72(1.47-2.08)$ & 0.000 & $1.40(1.09-1.78)$ & 0.007 \\
\hline Divorced/separated/widowed & 273 & 20.4 & $0.90(0.72-1.14)$ & 0.390 & $0.95(0.70-1.29)$ & 0.756 \\
\hline Educational level & & & & 0.000 & & \\
\hline Grade 7 or less & 459 & 14.8 & 1.00 & & 1.00 & \\
\hline Grade 8 to 11 & 957 & 21.3 & $1.56(1.29-1.88)$ & 0.000 & $1.62(1.28-2.04)$ & 0.000 \\
\hline Grade $12+$ & 1362 & 46.6 & $5.04(4.14-6.12)$ & 0.000 & $3.83(3.04-4.81)$ & 0.000 \\
\hline Population group & & & & 0.000 & & \\
\hline Black African & 1354 & 22.3 & 1.00 & & 1.00 & \\
\hline Other & 1422 & 39.8 & $2.30(1.97-2.68)$ & 0.000 & $1.21(1.02-1.44)$ & 0.028 \\
\hline
\end{tabular}


Table 2: Bivariate and multivarivate analyses of demographic factors associated with knowledge of HIV status among HIV positive and negative persons (Continued)

\begin{tabular}{|c|c|c|c|c|c|c|}
\hline \multicolumn{4}{|l|}{ Geolocality } & \multicolumn{3}{|l|}{0.000} \\
\hline Rural & 560 & 17.3 & 1.00 & & 1.00 & \\
\hline Urban & 2222 & 33.5 & $2.4 \mathrm{I}(2.06-2.8 \mathrm{I})$ & 0.000 & $1.58(1.31-1.91)$ & 0.000 \\
\hline Employment status & & & & 0.000 & & \\
\hline Not employed & 1393 & 19.9 & 1.00 & & 1.00 & \\
\hline Employed & 1330 & 40.7 & $2.76(2.35-3.25)$ & 0.000 & $1.93(1.58-2.35)$ & 0.000 \\
\hline
\end{tabular}

negative persons awareness of a place nearby where one could be tested for HIV, higher knowledge score on HIV and knowledge of serodiscordance were associated with knowledge of HIV status (see Table 4).

\section{Discussion}

The study found from a large nationally representative population-based HIV survey that $27.6 \%$ had knowledge of their HIV status, and $7.8 \%$ of the total sample had taken an HIV test in the past 12 months and knew their test result. Similar to this finding, more than half of Southern African countries have less than $10 \%$ of their population who know their HIV status (in the past 12 months) [3]. Evaluations of traditional VCT systems suggest low uptake of VCT even in places where access to VCT is unlimited [1]. As access to ART increases, there is an urgent need for alternative VCT delivery systems to increase access to and the utilization of VCT. These alternatives include mobile VCT, routine offer of counselling and testing and home-based VCT. These models can increase access to and the uptake of VCT [24].

This study found in multivariate analysis that being female, the age group 25 to 34 years old, other than African Black population group (White, Coloured, Asian), higher educational level, being employed, urban residence, awareness of a place nearby where one could be tested for HIV, impact of HIV on the household and two or more sexual partners in the past year were associated with knowledge of HIV status. Other studies also found that socio-economic factors such as age and being female [5-9], educational level $[6,10,11]$, occupation [7], area of residence [8], proximity and access to VCT site $[6,9,12,16,17]$, knowledge of VCT sites $[7,8]$ and HIV risk behaviour $[7,8,10,11,18,19]$ were associated with knowledge of HIV status. Rural residence, African Black population group, lower educational level and being unemployed were significantly associated with not knowing one's HIV status; clearly efforts should be made to make HIV testing available and promote HIV testing among these people.

In this study HIV knowledge, knowledge about ARVs, HIV risk perception, HIV status, history of STI and AIDS stigma and discrimination were in multivariate analyses not found to be associated with knowledge of HIV status, unlike in findings from other studies where fear of unsolicited disclosure, fear of stigma and discrimination $[1,6,7,9,12]$, marital status [8], HIV knowledge, HIV risk perception $[7,8,10,11,18,19]$ and health status $[5,7,8]$ were associated with knowledge of HIV status or HIV testing. The knowledge about ARVs was in this study not significantly related to knowing one's HIV status. The ART roll out in the public health sector had begun in South Africa in 2003, and one could have expected that more people get tested for HIV knowing about ARVs and thus accessing ART. It may be possible that in 2005 at the time of the survey antiretroviral treatment was not yet widely known and accessible; $39.5 \%$ of the survey respondents indicated that they had not heard about antiretroviral treatment.

The study found that among HIV positive persons awareness of a place nearby where one could be tested for HIV and impact of HIV on the household were associated knowledge of HIV status, and among HIV negative persons HIV risk behaviour (multiple partners, no condom use), awareness of a place nearby where one could be tested for HIV, higher knowledge score on HIV and knowledge of serodiscordance were associated knowledge of HIV status. The finding that HIV risk behaviour was associated with HIV test utilization among HIV negative persons seem to concur with the finding that VCT utilization is higher among low HIV risk groups [7,13]. With the increase in both educational level and knowledge of HIV/ AIDS, accurate information about the disease and its causes and modes of transmission will be conveyed which seem to have led to HIV testing among HIV negative persons. In addition, sexual risk behaviour was associated with knowledge of HIV status among HIV negative persons, yet HIV risk perception was not found a predictor for knowledge of HIV status. The impact of HIV on the household was highly associated with knowledge of HIV status among HIV positive but not with HIV negative persons. Knowing someone living with or caring for someone with HIV and AIDS or someone who had died from AIDS was associated with knowledge of HIV status. With high rates of HIV in families and communities in South Africa there is an increased likelihood of knowing someone infected by the disease but it can also be that the respondent in these families are more likely to have been diagnosed with HIV themselves. 
Table 3: Bivariate and multivarivate analyses of behavioural factors associated with knowledge of HIV status among HIV positive and negative persons

\begin{tabular}{|c|c|c|c|c|c|c|}
\hline \multirow[t]{2}{*}{ Behavioural factors } & \multicolumn{6}{|c|}{ HIV positive } \\
\hline & $\mathrm{N}$ & Know HIV test result (\%) & Crude OR (95\% Cl) & P-value & $\begin{array}{l}\text { Adjusted OR }(95 \% \mathrm{Cl})^{\prime} \\
\text { (Pseudo R square }=.02)\end{array}$ & P-value \\
\hline $\begin{array}{l}\text { Number of sexual partners } \\
\text { (past year) }\end{array}$ & & & & 0.532 & & \\
\hline None & 109 & 30.5 & 1.00 & & --- & \\
\hline One & 295 & 33.6 & $1.15(0.78-1.70)$ & 0.471 & & \\
\hline Two or more & 32 & 32.6 & $1.10(0.55-2.20)$ & 0.782 & & \\
\hline No condom use at last sex & & & & 0.383 & & \\
\hline No & 176 & 40.8 & 1.00 & & --- & \\
\hline Yes & 98 & 35.9 & $0.81(0.5 \mathrm{I}-1.29)$ & 0.383 & & \\
\hline $\begin{array}{l}\text { No condom use with last non- } \\
\text { regular partner }\end{array}$ & & & & 0.665 & & \\
\hline No & 29 & 36.0 & 1.00 & & --- & \\
\hline Yes & 32 & 40.4 & $1.20(0.52-2.78)$ & 0.665 & & \\
\hline Ever STI symptoms & & & & 0.491 & & \\
\hline No & 371 & 33.4 & 1.00 & & & \\
\hline Yes & 31 & 29.1 & $0.82(0.46-1.46)$ & 0.491 & & \\
\hline Behavioural factors & & & HIV ne & gative & & \\
\hline $\begin{array}{l}\text { Number of sexual partners } \\
\text { (past year) }\end{array}$ & & & & 0.000 & & \\
\hline None & 652 & 13.6 & 1.00 & & 1.00 & \\
\hline One & 1992 & 35.6 & $3.50(2.97-4.13)$ & 0.000 & $1.71(1.29-2.27)$ & 0.000 \\
\hline Two or more & 138 & 32.5 & $3.06(2.16-4.33)$ & 0.000 & $1.60(1.04-2.45)$ & 0.032 \\
\hline No condom use at last sex & & & & 0.000 & & \\
\hline No & 768 & 34.8 & 1.00 & & 1.00 & \\
\hline Yes & 841 & 45.8 & $1.59(1.24-2.02)$ & 0.000 & $1.58(1.23-2.02)$ & 0.000 \\
\hline $\begin{array}{l}\text { No condom use with last non- } \\
\text { regular partner }\end{array}$ & & & & 0.405 & & \\
\hline No & 141 & 38.7 & 1.00 & & & \\
\hline Yes & 186 & 34.5 & $0.83(0.55-1.28)$ & 0.405 & --- & \\
\hline Ever STI symptoms & & & & 0.609 & --- & \\
\hline No & 2366 & 26.3 & 1.00 & & & \\
\hline Yes & 104 & 28.2 & $1.10(0.77-1.57)$ & 0.609 & & \\
\hline
\end{tabular}

ladjusted for sex and age

\section{Limitations}

Caution should be taken when interpreting the results of this study due to certain limitations. Since this was a crosssectional study, causality between the compared variables cannot be concluded. A further limitation was that a number of factors known to be contributing to knowledge of HIV status were not assessed, which included attitudes towards and desire for HIV testing [1,25]. Some measures in this study were limited in length, e.g. HIV risk perception and ARV knowledge was only measured with one item. The HIV testing and risk history measures did not include assessments of time since the behaviours occurred, not allowing us to examine whether people who were recently tested or who recently engaged in risk activities differed from those practising these behaviours less recently.

\section{Conclusion}

In this setting, a disproportionate number of HIV-positive young, lower educated Black African rural men are failing to learn their status, which has implications for equitable access to onward referral for care and treatment services. 
Table 4: Bivariate and multivarivate analyses of HIV knowledge and risk factors associated with knowledge of HIV status among HIV positive and negative persons

\begin{tabular}{|c|c|c|c|c|c|c|}
\hline \multirow{2}{*}{$\begin{array}{l}\text { HIV knowledge and risk } \\
\text { variables }\end{array}$} & \multicolumn{6}{|c|}{ HIV positive } \\
\hline & $\mathrm{N}$ & Know HIV test result (\%) & Crude OR $(95 \% \mathrm{Cl})$ & P-value & $\begin{array}{l}\text { Adjusted OR }(95 \% \mathrm{Cl}) \mid \\
\text { (Pseudo R square }=.13)\end{array}$ & P- value \\
\hline $\begin{array}{l}\text { Aware of place nearby place to get } \\
\text { tested for HIV }\end{array}$ & & & & 0.000 & & \\
\hline No & 9 & 5.1 & 1.00 & & 1.00 & \\
\hline Yes & 426 & 38.6 & II.7 (4.56-29.87) & 0.000 & $8.85(3.40-23.0)$ & 0.000 \\
\hline HIV knowledge & & & & 0.092 & & \\
\hline Low & 102 & 29.4 & 1.00 & & & \\
\hline Medium & 146 & 29.9 & $1.03(0.66-1.59)$ & 0.903 & & \\
\hline High & 179 & 37.0 & $1.41(0.93-2.14)$ & 0.107 & --- & \\
\hline Knowledge of $A R V s$ & & & & 0.420 & & \\
\hline No & 151 & 30.6 & 1.00 & & & \\
\hline Yes & 283 & 33.6 & $1.15(0.82-1.62)$ & 0.420 & --- & \\
\hline Know of serodiscordance & & & & 0.000 & & \\
\hline No & 180 & 27.4 & 1.00 & & 1.00 & \\
\hline Yes & 255 & 38.2 & $5.94(3.52-10.04)$ & 0.000 & $1.39(0.96-1.99)$ & 0.077 \\
\hline $\begin{array}{l}\text { Impact of HIV } \\
\text { (household: HIV, care death) }\end{array}$ & & & & 0.000 & & \\
\hline No & 342 & 28.2 & 1.00 & & 1.00 & \\
\hline Yes & 94 & 70.0 & $5.94(3.52-10.04)$ & 0.000 & $4.60(2.54-8.32)$ & 0.000 \\
\hline HIV risk perception & & & & 0.000 & & \\
\hline Low & 57 & 19.1 & 1.00 & & 1.00 & \\
\hline Medium & 115 & 29.1 & $1.74(1.04-2.90)$ & 0.034 & $1.38(0.78-2.46)$ & 0.269 \\
\hline High & 254 & 39.4 & $2.75(1.03-4.37)$ & 0.000 & I.7I (1.02-2.89) & 0.042 \\
\hline AIDS stigma attitudes & & & & 0.997 & & \\
\hline Low & 192 & 32.9 & 1.00 & & & \\
\hline Medium & 198 & 33.3 & $1.02(0.72-1.44)$ & 0.928 & --- & \\
\hline High & 41 & 32.4 & $0.98(0.53-1.79)$ & 0.939 & & \\
\hline
\end{tabular}

HIV knowledge and risk variables

HIV negative

\begin{tabular}{|c|c|c|c|c|c|c|}
\hline \multicolumn{3}{|l|}{$\begin{array}{l}\text { Aware of place nearby place to get } \\
\text { tested for HIV }\end{array}$} & \multicolumn{3}{|c|}{0.000} & \multirow[b]{3}{*}{0.000} \\
\hline No & 92 & 4.1 & 1.00 & & 1.00 & \\
\hline Yes & 2682 & 32.9 & $11.6(8.23-16.29)$ & 0.000 & $9.73(6.90-13.73)$ & \\
\hline HIV knowledge & & & & 0.000 & & \\
\hline Low & 601 & 17.1 & 1.00 & & 1.00 & \\
\hline Medium & 962 & 29.0 & $1.98(1.64-2.39)$ & 0.000 & $1.46(1.18-1.80)$ & 0.001 \\
\hline High & 1181 & 32.2 & $2.30(1.94-2.74)$ & 0.000 & $1.64(1.36-1.97)$ & 0.000 \\
\hline Knowledge of $A R V_{s}$ & & & & 0.224 & & \\
\hline No & 938 & 25.3 & 1.00 & & & \\
\hline Yes & 1838 & 27.1 & $1.10(0.95-1.27)$ & 0.224 & --- & \\
\hline Know of serodiscordance & & & & 0.000 & & \\
\hline No & 951 & 20.1 & 1.00 & & 1.00 & \\
\hline Yes & 1823 & 32.0 & $1.87(1.62-2.17)$ & 0.000 & $1.56(1.31-1.85)$ & 0.000 \\
\hline
\end{tabular}


Table 4: Bivariate and multivarivate analyses of HIV knowledge and risk factors associated with knowledge of HIV status among HIV positive and negative persons (Continued)

\begin{tabular}{llllll}
\hline $\begin{array}{l}\text { Impact of HIV } \\
\text { (household: HIV, care death) }\end{array}$ & 2660 & 26.1 & \multicolumn{3}{c}{0.024} \\
$\begin{array}{l}\text { No } \\
\text { Yes }\end{array}$ & 122 & 33.4 & 1.00 & & 1.00 \\
& & & $1.43(1.05-1.94)$ & 0.024 & $1.22(0.86-1.73)$ \\
\hline HIV risk perception & 983 & 24.0 & & 0.013 & \\
Low & 924 & 27.1 & 1.00 & & 1.00 \\
Medium & 870 & 28.3 & $1.17(0.99-1.40)$ & 0.071 & $1.05(0.88-1.26)$ \\
High & & & $1.25(1.05-1.49)$ & 0.014 & $0.96(0.79-1.18)$ \\
\hline AIDS stigma attitudes & 1152 & 27.5 & & 0.267 \\
Low & 1333 & 26.0 & 1.00 & & \\
Medium & 273 & 25.1 & $0.93(0.80-1.08)$ & 0.335 & --- \\
High & & $0.88(0.69-1.13)$ & 0.324 & \\
\hline
\end{tabular}

'Adjusted for sex and age

Evidence that some high-risk behaviour may prompt HCT use is encouraging, although further interventions are required to improve knowledge about HIV risk and the benefits of HCT. Targeted interventions are also needed to promote HCT uptake among single, young and older persons and rural residents. For, example the use of mobile HCT (the provision of HIV counselling and testing services by mobile teams from a van equipped with HIV-testing facilities) can improve access for hard-to-reach and rural populations. The study findings further indicate that many persons in South Africa have never known their HIV status. Health-care providers should routinely screen all patients for HIV. New strategies such as mobile and home-based HCT are warranted to increase HIV testing, particularly among persons who are disproportionately affected by HIV infection.

\section{Competing interests}

The authors declare that they have no competing interests.

\section{Authors' contributions}

$\mathrm{KP}, \mathrm{GM}$, TM and MM conceptualized, analysed and interpreted the secondary data, drafted and revised the manuscript. All authors read and approved the final draft of the manuscript.

\section{Acknowledgements}

The authors wish to acknowledge the provision of the data set and the time provided by the HSRC to write this paper.

\section{References}

I. Kalichman SC, Simbayi LC: HIV testing attitudes, AIDS stigma, and voluntary HIV counselling and testing in a black township in Cape Town, South Africa. Sex Transm Infect 2003, 79(6):442-447.

2. Bunnell R, Opio A, Musinguzi J, Kirungi W, Ekwaru P, Mishra V, Hladik W, Kafuko J, Madraa E, Mermin J: HIV transmission risk behavior among HIV-infected adults in Uganda: results of a nationally representative survey. AIDS 2008, 22(5):617-24.

3. SADC: 2007 SADC HIV and AIDS Epidemic Report. Gaberone: SADC; 2008
4. Centers for Disease Control and Prevention (CDC): Persons tested for HIV - United States, 2006. MMWR Morb Mortal Wkly Rep 2008, 57(31):845-9.

5. Shisana O, Rehle T, Simbayi LC, Parker W, Zuma K, Bhana A, Connolly $C$, Jooste $S$, Pillay V: South African national HIV prevalence, HIV incidence, behaviour and communication survey. Cape Town: HSRC Press; 2005.

6. Hutchinson PL, Mahlalela X: Utilization of voluntary counseling and testing services in the Eastern Cape, South Africa. AIDS Care 2006, I 8(5):446-55.

7. Ma W, Detels R, Feng Y, Wu Z, Shen L, Li Y, Li Z, Chen F, Wang A, Liu T: Acceptance of and barriers to voluntary HIV counselling and testing among adults in Guizhou province, China. AIDS 2007, 2 I (Suppl 8):SI29-35.

8. Wringe A, Isingo R, Urassa M, Maiseli G, Manyalla R, Changalucha J, Mngara J, Kalluvya S, Zaba B: Uptake of HIV voluntary counselling and testing services in rural Tanzania: implications for effective HIV prevention and equitable access to treatment. Trop Med Int Health 2008, I3(3):3 I9-27.

9. Bwambale FM, Ssali SN, Byaruhanga S, Kalyango JN, Karamagi CA: Voluntary HIV counselling and testing among men in rural western Uganda: implications for HIV prevention. BMC Public Health 2008, 30(8):263.

10. Gage AJ, Ali D: Factors associated with self-reported HIV testing among men in Uganda. AIDS Care 2005, I 7(2): 153-65.

II. Haile BJ, Chamber JW, Garrison JL: Correlates of HIV knowledge and testing: Results of a 2003 South African HIV Survey. J Black Studies 2007, 38: 194-208.

12. Morin SF, Khumalo-Sakutukwa G, Charlebois ED, Routh J, Fritz K, Lane T, Vaki T, Fiamma A, Coates TJ: Removing barriers to knowing HIV status: same-day mobile HIV testing in Zimbabwe. J Acquir Immune Defic Syndr 2006, 41:2 I8-224.

13. Obermeyer CM, Osborn M: The utilization of Testing and Counseling for HIV: A review of the social and behavioral evidence. Am J Pub Health 2007, 97( 10): 1762-1774.

14. Radebe MA: Perceptions of employees about Voluntary Counselling and testing at a motor manufacturing industry. In MA Thesis University of Pretoria: Pretoria, Department of Social Work and Criminology; 2006.

15. Varga C, Brookes H: Factors influencing teen mothers' enrollment and participation in prevention of mother-to-child HIV transmission services in Limpopo Province, South Africa. Qual Health Res 2008, 18(6):786-802.

16. Birdsall K, Hajiyiannis H, Nkosi Z, Parker W: Voluntary Counselling and Testing (VCT) in South Africa: Analysis of calls to the national AIDS helpline. Johannesburg: Centre for Aids Development, Research and Evaluation (CADRE); 2004.

17. Pronyk PM, Kim JC, Makhubele MB, Hargreaves JR, Mohlala R, Hausler HP: Introduction of voluntary counselling and rapid testing for HIV in rural South Africa: from theory to practice. AIDS Care 2002, 14(6):859-65.

18. Boulle A, Hilderbrand K, Menten J, Coetzee D, Ford N, Matthys F, Boelaert $M$, Stuyft $P$ Van der: Exploring HIV risk perception and behaviour in the context of antiretroviral treatment: results 
from a township household survey. AIDS Care 2008, 20(7):77I-8I.

19. Mutevedzi T, Routh J, Khumalo-Sakutukwa G, Fritz K, Morin S: Removing barriers to knowing HIV status: A comparison of testers and non-testers in Sub-Saharan Africa. 2002 [http:// www.aegis.com/conferences/iac/2002/LbPeD9042.html]. Paper presented at the Collaborative Research Programme in Women's Health, the University of Zimbabwe and the University of San Francisco

20. Etiebet MA, Fransman D, Forsyth B, Coetzee N, Hussey G: Integrating prevention of mother-to-child HIV transmission into antenatal care: learning from the experiences of women in South Africa. AIDS Care 2004, I6(I):37-46.

21. Doherty TM, McCoy D, Donohue S: Health system constraints to optimal coverage of the prevention of mother-to-child HIV transmission programme in South Africa: lessons from the implementation of the national pilot programme. Afr Health Sci 2005, 5(3):213-8.

22. Coovadia HM: Access to voluntary counseling and testing for HIV in developing countries. Ann N Y Acad Sci 2000, 91 8:57-63.

23. Cartoux M, Meda N, Perre P Van de, Newell ML, de Vicenzi I, Dabis F: Acceptability of voluntary HIV testing by pregnant women in developing countries: an international survey. AIDS 1998, I 2( 1 8):2489-2493.

24. Matovu JK, Makumbi FE: Expanding access to voluntary HIV counselling and testing in sub-Saharan Africa: alternative approaches for improving uptake, 200I-2007. Trop Med Int Health 2007, I 2(II): 13 I5-22.

25. Mbago MC: Socio-demographic correlates of desire for HIV testing in Tanzania. Sex Health 2004, I(I): I3-2I.

\section{Pre-publication history}

The pre-publication history for this paper can be accessed here:

http://www.biomedcentral.com/1471-2458/9/174/pre

pub

Publish with Bio Med Central and every scientist can read your work free of charge

"BioMed Central will be the most significant development for disseminating the results of biomedical research in our lifetime. "

Sir Paul Nurse, Cancer Research UK

Your research papers will be:

- available free of charge to the entire biomedical community

- peer reviewed and published immediately upon acceptance

- cited in PubMed and archived on PubMed Central

- yours - you keep the copyright 